\title{
Glutathione S- Transferase as a Marker of Acute Kidney Injury in Pediatric Intensive Care, Zagazig University Children Hospital Samir M. Zamzam ${ }^{1}$, Nehad AK Abd Elfatah ${ }^{1}$, Noha AM Rezk ${ }^{2}$, Magdi MH Soliman ${ }^{* 1}$ \\ Departments ${ }^{1}$ Pediatrics and ${ }^{2}$ Medical Biochemistry, Faculty of Medicine, Zagazig University, Egypt. \\ *Corresponding author: Magdi Mohamed Hossam El-Din Soliman, Mobile: (+20)1030804508, \\ Email: magdisoliman.1973@gmail.com
}

\begin{abstract}
Background: Glutathione S-transferases (GST) are major phase II detoxification enzymes having central roles in the cellular detoxication of a diverse group of exogenous and endogenous harmful compounds.

Objective: The aim of the work was to investigate the role of GST in development of acute kidney injury in PICU, Zagazig University Children Hospital.

Patients and Methods: A prospective cohort study was conducted on 50 pediatric patients admitted to PICU who were divided into two groups according to incidence of Acute Kidney Injury (AKI). Patients were subjected to clinical, laboratory, and plasma \& urinary GST evaluation.

Results: AKI developed in $24 \%$ of patients. There was no significant relation between presence of AKI and patient age, gender, weight, height, or clinical outcome. There were significant relations between plasma and urine GST and presence of AKI. There is statistically non-significant relation between Pediatric Risk, Injury, Failure, Loss, End-Stage renal disease (pRIFLE) staging and plasma and urine GST. There were statistically significant negative correlations between each of plasma and urine GST on one side and both heart rate and estimated creatinine clearance on the other side. Plasma GST can predict presence of AKI at cutoff $\geq 30.5$, with AUC 0.964 , sensitivity $100 \%$, specificity $84 . \%$, PPV $66.7 \%$, NPV $100 \%$, accuracy $88 \%$. Urinary GST in prediction of AKI was $\geq 12.5$, with AUC 0.95 , sensitivity $91.7 \%$, specificity $84.2 \%$, with accuracy $86 \%$.

Conclusion: It could be concluded that AKI had significant incidence in PICU admission. High levels of plasma and urine GST Pi after admission in PICU are associated with an increased development of AKI and GST Pi is a valuable tool for early diagnosis of AKI.
\end{abstract}

Keywords: Kidney injury, Glutathione Transferase.

\section{INTRODUCTION}

Acute kidney injury (AKI) is defined as the abrupt loss of kidney function that results in a decline in glomerular filtration rate (GFR), retention of urea and other nitrogenous waste products, and dysregulation of extracellular volume and electrolytes. The term AKI has largely replaced acute renal failure (ARF), as more clearly defines renal dysfunction as a continuum rather than a discrete finding of failed kidney function ${ }^{(\mathbf{1})}$.

If renal function of the patient returns to baseline within $48 \mathrm{~h}$, this is called rapid reversal AKI while persistent AKI is beyond 48 hrs. If renal dysfunction that persists for 7 days is categorized as Acute Kidney Disease (AKD) and the term Chronic Kidney Disease (CKD) is used for patients with kidney disease persistent after 90 days period ${ }^{\text {(2) }}$.

The role of creatinine as a marker of renal function is not enough, by the fact that its half-life increases from $4 \mathrm{~h}$ to $24-72 \mathrm{~h}$ if the glomerular filtration rate (GFR) decreases. Rise of serum concentration may take $24-36 \mathrm{~h}$ after a definite renal insult. True decrease in GFR may not be adequately reflected by serum creatinine in cases with sepsis, liver disease, and/or muscle wasting ${ }^{(3-4)}$.

Some of new biomarkers e.g. (Cystatin C, Glutathione S-Transferase, Alkaline phosphatase and Angiopoiten 1 and 2) may also provide information about the underlying etiology and indicate different stages of the pathophysiological processes involved in AKI from acute stage to recovery ${ }^{(5)}$.

The GST protein family, which is divided into 3 major subclasses alpha ,bi, gamma are ubiquitous enzymes which have a role in the detoxification of free radicals .The GST proteins family have been purified from a wide variety of human tissues (e.g. kidneys, testes ovaries, small intestine, liver and adrenal glands). In renal tubules contain alpha and pi forms in high amounts thus GST is a good marker for diagnosis of AKI ${ }^{(6)}$.

This study was aimed to find and investigate the role of GST in development and outcome of acute kidney injury in PICU of Zagazig University Children Hospital.

\section{PATIENT AND METHODS}

This prospective, cohort study included a total of 50 critically ill infants and children, attending at PICU, Faculty of Medicine, Zagazig University Children Hospital. This study was conducted between September 2018 to end of February 2019.

Approval for doing the research was obtained from Pediatrics and Medical Biochemistry Departments, Zagazig University, after receiving Institutional Review Board (IRB) approval. The 
study was done according to The Code of Ethics of the World Medical Association (Declaration of Helsinki) for studies involving humans. Written informed consent of all the subject parents was obtained.

\section{Inclusion criteria}

- Patient's age from 1 month up to 16 years.

- Patient with admission more than 24 hours

- Both males and females were included.

\section{Exclusion criteria}

- Patient with chronic kidney injury and those admitted for less than 24 hours.

The included subjects were divided into two groups; Non-AKI Group (control) consisted of 38 Infants and children who lack the diagnostic criteria of acute kidney injury and AKI Group (cases) consisted of 12 Infants and children who developed acute kidney injury (AKI).

\section{AKI was diagnosed according to:}

A- pRIFLE criteria ${ }^{(7)}$ :

- RISK (eCC decreased by $25 \%, \mathrm{UOP}$ less than 0.5 $\mathrm{ml} / \mathrm{kg} / \mathrm{h}$. for 8 hours).

- Injury(eCC decreased by $50 \%, \mathrm{UOP}$ less than 0.5 $\mathrm{ml} / \mathrm{kg} /$ hour for 16 hours).

- Failure(eCC decreased by $75 \%$ or eCC less than 35 $\mathrm{ml} / \mathrm{min} / 1.73 \mathrm{~m}^{2}$,UOP less than $0.3 \mathrm{ml} / \mathrm{kg} / \mathrm{h}$.for 24 hours) or anuric for $12 \mathrm{~h}$.

- Loss (persistent failure more than 4 weeks).

- End stage renal disease (persistent failure more than 3 months).

\section{B- KDIGO stages ${ }^{(8)}$ :}

Stage 1: One of the following:

- Serum creatinine increased 1.5-1.9 times baseline.

- Serum creatinine increase $>0.3 \mathrm{mg} / \mathrm{dl}$ $(26.5 \mu \mathrm{mol} / \mathrm{l})$.

- Urinary output $<0.5 \mathrm{ml} / \mathrm{kg} / \mathrm{h}$ during a 6-hour block.

Stage 2: One of the following:

- Serum creatinine increase 2.0-2.9 times baseline.

- Urinary output $<0.5 \mathrm{ml} / \mathrm{kg} / \mathrm{h}$ during two 6 hours blocks.

Stage 3: One of the following:

- Serum creatinine increase 3 times baseline.

- Serum creatinine increases to $>4.0 \mathrm{mg} / \mathrm{dl}$ $(353 \mu \mathrm{mol} / 1)$.

- Initiation of renal replacement therapy.

- Urinary output $<0.3 \mathrm{ml} / \mathrm{kg} / \mathrm{h}$ during more than 24 hours.

- Anuria for more than 12 hours.

\section{Study Assessments and Data Collection}

For each eligible patient, the following data was reported:

- Full history taken: personal history, history of present Illness, past history, perinatal history, developmental, dietetic, vaccination and family history.

- Complete clinical examination: general and local with stress on: Vital signs, Hydration of the patients and capillary refill.

- Investigations:

Venous blood was withdrawn to perform serum and urine Glutathione S-Transferase, complete blood picture, Complete urine analysis,

Calculation of urine output, serum electrolytes, serum urea and creatinine, abdominal ultrasound(if needed).

Estimated creatinine clearance $(\mathrm{eCC})$ was calculated according to the Schwartz formula. eGFR $\left(\mathrm{ml} / \mathrm{min} / 1.73 \mathrm{~m}^{2}\right)=\mathbf{k} \times$ length $(\mathrm{cm}) /$ Serum creatinine $(\mathrm{mg} / \mathrm{dl})$.

Where (k) is 0.33 for low-birth weight infants $<1 \mathrm{yr}$. old, 0.45 for term infants $<1 \mathrm{yr}$ old whose weight is appropriate for gestational age, 0.55 for children and adolescent girls, and 0.70 for adolescent boys ${ }^{(9)}$.

Serum and urine Glutathione S-Transferase determination were done by using a doubleantibody sandwich enzyme-linked immune-sorbent assay (ELISA).

\section{Statistical analysis}

Data were analyzed by Statistical Package of Social Science (SPSS), software version 24.0. Continuous data were presented as the Mean \pm SD if normally distributed or Median (Range) if not normally distributed. Normality was checked by Shapiro test. Categorical data were presented by the count and percentage. Chi-squared test: is used to discover if there is a relationship between two categorical variables. Independent-samples $t$-test: is used to determine if a difference exists between the means of two independent groups on a continuous dependent variable. Mann-Whitney $u$ test (nonparametric alternative to independent-samples ttest).Fisher's Exact Test: for (2X2) (RXC) table. It is an alternative to chi-squared test when the expected cell count is less than five. Pearson's and Spearman correlation coefficients were used to estimate is the strength of linear relationship between two continuous variables; at least one of the two variables must follow a normal and not normal distribution respectively. $P$-value $<0.05$ indicates significant difference and $P$-value $\geq 0.05$ indicates non-significant difference 


\section{RESULTS}

AKI developed in $24 \%$ of patients (table 1). The current study showed that there was statistically non-significant relation between presence of AKI and patient age, gender, weight or height (Table 1). Also, there was statistically non-significant relation between presence of AKI and fate of patients (table 2)

On assessing relation between GST in urine and plasma and presence of AKI, statistically highly significant relations were detected (table 3). There was statistically non-significant relation between pRIFLE staging and GST (plasma and urine) (Table 4).

There were statistically significant negative correlations between each of plasma and urine GST on one side and both heart rate and estimated creatinine clearance on the other side (Table 5). There was statistically non-significant correlation between either plasma, urine GST and age, height, weight, other vital signs or other laboratory parameters (Table $5)$.

Plasma GST could predict presence of AKI at cutoff $\geq 30.5$, with AUC 0.964 , sensitivity $100 \%$, specificity $84 \%$, PPV $66.7 \%$, NPV $100 \%$, positive likelihood ratio 6.6 and negative likelihood ratio 0 with accuracy $88 \%$ (Figure 1)

The best cutoff of urinary GST in prediction of AKI was $\geq 12.5$, with AUC 0.95, sensitivity 91.7\%, specificity $84.2 \%$, PPV $64.7 \%$, NPV 97\%, positive likelihood ratio 5.8 and negative likelihood ratio 0.1 with accuracy $86 \%$ (Figure 2).

Table (1): Comparison between patients with and without AKI regarding demographic characteristics:

\begin{tabular}{|c|c|c|c|c|c|c|}
\hline & \multicolumn{2}{|c|}{$\begin{array}{c}\text { Non-AKI } \\
\text { No }=38\end{array}$} & \multicolumn{2}{|c|}{$\begin{array}{c}\text { AKI } \\
\text { No= }=12\end{array}$} & $\begin{array}{l}\text { Test } \\
\text { of sig. }\end{array}$ & $\mathbf{P}$ \\
\hline $\begin{array}{l}\text { Age (month) } \\
\text { Median (Range) }\end{array}$ & \multicolumn{2}{|c|}{$7(1.03-144)$} & \multicolumn{2}{|c|}{$9(1.6-156)$} & $Z(-1.493)$ & 0.135 \\
\hline $\begin{array}{l}\text { Height }(\mathrm{cm}) \\
\text { Median }\end{array}$ & \multicolumn{2}{|c|}{63} & \multicolumn{2}{|c|}{71} & $\mathrm{Z}(-0.671)$ & 0.502 \\
\hline $\begin{array}{l}\text { Weight }(\mathrm{kg}) \\
\text { Median }\end{array}$ & \multicolumn{2}{|c|}{6} & \multicolumn{2}{|c|}{8} & $\mathrm{Z}(-0.273)$ & 0.785 \\
\hline & $\mathrm{N}=38$ & $\%$ & $\mathrm{~N}=12$ & $\%$ & $\chi^{2}$ & $\mathbf{P}$ \\
\hline $\begin{array}{l}\text { Gender: } \\
\text { Male } \\
\text { Female }\end{array}$ & $\begin{array}{l}19 \\
19\end{array}$ & $\begin{array}{l}50 \\
50\end{array}$ & $\begin{array}{c}2 \\
10\end{array}$ & $\begin{array}{l}16.7 \\
83.3\end{array}$ & Fisher & 0.051 \\
\hline
\end{tabular}

(Z):Mann-Whitney test; $\left(\chi^{2}\right)$ :Chi -square test. ; $\mathbf{p}>0.05$ is statistically non-significant.

Table (2): Comparison between patients with and without AKI regarding outcome:

\begin{tabular}{|l|c|c|c|c|c|c|}
\hline \multirow{2}{*}{ Outcome } & \multicolumn{2}{|c|}{$\begin{array}{c}\text { Non-AKI } \\
\text { No=38 }\end{array}$} & \multicolumn{2}{|c|}{$\begin{array}{c}\text { AKI } \\
\text { No=12 }\end{array}$} & \multirow{2}{*}{$\boldsymbol{\chi}^{\mathbf{2}}$} & \multirow{2}{*}{$\mathbf{p}$} \\
\cline { 2 - 5 } & $\mathbf{N}$ & $\mathbf{\%}$ & $\mathbf{N}$ & $\mathbf{\%}$ & & \multirow{2}{*}{0.448} \\
\hline \multirow{2}{*}{ Died } & & & & & & \\
Survived & 30 & 21.1 & 4 & 33.3 & Fisher & \\
\hline
\end{tabular}

$\chi^{2}$ : Chi square test, $\mathbf{p}<\mathbf{0 . 0 5}$ is statistically significant.

Table (3): Comparison between patients with and without AKI regarding plasma and urine GST:

\begin{tabular}{|l|l|c|c|c|}
\hline & \multicolumn{1}{|c|}{$\begin{array}{c}\text { Non-AKI } \\
\text { No=38 }\end{array}$} & $\begin{array}{c}\text { AKI } \\
\text { No=12 }\end{array}$ & $\begin{array}{c}\text { Test of } \\
\text { Sig. }\end{array}$ & p \\
\hline Plasma GST ( $\boldsymbol{\mu g} / \mathbf{L})$ & $19.26 \pm$ & $39 \pm 3.54$ & $\mathrm{Z}(-4.815)$ & $<0.001$ \\
$($ Mean \pm SD) & 4.46 & & $\mathrm{t}(-7.697)$ & $<0.001$ \\
\hline $\begin{array}{l}\text { Urine GST (mg/L) } \\
\text { Mean } \pm \text { SD) }\end{array}$ & $10.68 \pm 2.08$ & $16.58 \pm$ & 2.97 & \\
\hline
\end{tabular}

(Z):Mann-Whitney test ; (t): independent sample t test.; $\mathrm{p} \leq 0.001$ is statistically significant 
Table (4): Comparison between plasma and urine GST regarding pRIFLE in the studied patients:

\begin{tabular}{|c|c|c|c|c|c|}
\hline & $\mathbf{R}$ & I & $\mathbf{F}$ & \multirow[b]{2}{*}{$\mathbf{t}$} & \multirow[b]{2}{*}{$\mathbf{P}$} \\
\hline & $\begin{array}{l}\text { Mean } \pm \\
\text { SD }\end{array}$ & Mean \pm SD & Mean \pm SD & & \\
\hline $\begin{array}{l}\text { Plasma } \\
\text { GST }(\mu \mathrm{g} / \mathrm{L})\end{array}$ & $37 \pm 5.19$ & $39 \pm 2.738$ & $39.25 \pm 4.349$ & 0.209 & $\mathbf{0 . 8 3 9}$ \\
\hline $\begin{array}{l}\text { Urine GST } \\
(\mathrm{mg} / \mathrm{L})\end{array}$ & $17.66 \pm 4.04$ & $16.8 \pm 2.949$ & $16 \pm 1.414$ & 2.017 & 0.071 \\
\hline
\end{tabular}

p>0.05 is statistically significant, (t): independent sample t test, $(\mathbf{T})$ :T test ; $(\mathbf{R})$ :Risk; (I):Injury; (F):Failure.

Table (5): Correlation between plasma GST and vital signs in the studied patients:

\begin{tabular}{|l|l|l|l|l|}
\hline \multirow{2}{*}{} & \multicolumn{2}{|c|}{ Plasma GST } & \multicolumn{2}{c|}{ Urine GST } \\
\cline { 2 - 5 } & $\mathbf{r}$ & $\mathbf{p}$ & $\mathbf{r}$ & $\mathbf{p}$ \\
\hline Age (month) & 0.233 & 0.103 & 0.234 & 0.103 \\
\hline Temperature (C $\left.{ }^{\circ}\right)$ & -0.193 & 0.179 & -0.076 & 0.639 \\
\hline Respiratory rate /min & -0.07 & 0.639 & 0.001 & 0.996 \\
\hline Heart rate /min & -0.337 & $0.017^{*}$ & -0.303 & $0.032^{*}$ \\
\hline Systolic blood pressure (mmHg) & 0.004 & 0.977 & 0.079 & 0.585 \\
\hline Diastolic blood pressure (mmHg) & 0.092 & 0.524 & 0.266 & 0.062 \\
\hline TLC & -0.132 & 0.361 & 0.071 & 0.622 \\
\hline Platelet count & -0.168 & 0.243 & -0.08 & 0.580 \\
\hline Hemoglobin $(\mathrm{g} / \mathrm{dl})$ & -0.105 & 0.466 & -0.110 & 0.449 \\
\hline eCC (ml/min) & -0.345 & $0.014 *$ & -0.318 & 0.024 \\
\hline Urea & 0.425 & 0.002 & 0.252 & 0.078 \\
\hline Sodium (mmol/L) & -0.218 & 0.127 & -0.036 & 0.806 \\
\hline Potassium (mmol/L ) & -0.174 & 0.228 & 0.045 & 0.757 \\
\hline Calcium (mg/dL ) & -0.214 & 0.136 & -0.158 & 0.272 \\
\hline Duration of stay in PICU & 0.161 & 0.236 & 0.2 & 0.165 \\
\hline Duration of stay on MV & -0.255 & 0.306 & -0.260 & 0.298 \\
\hline
\end{tabular}

r Correlation coefficient

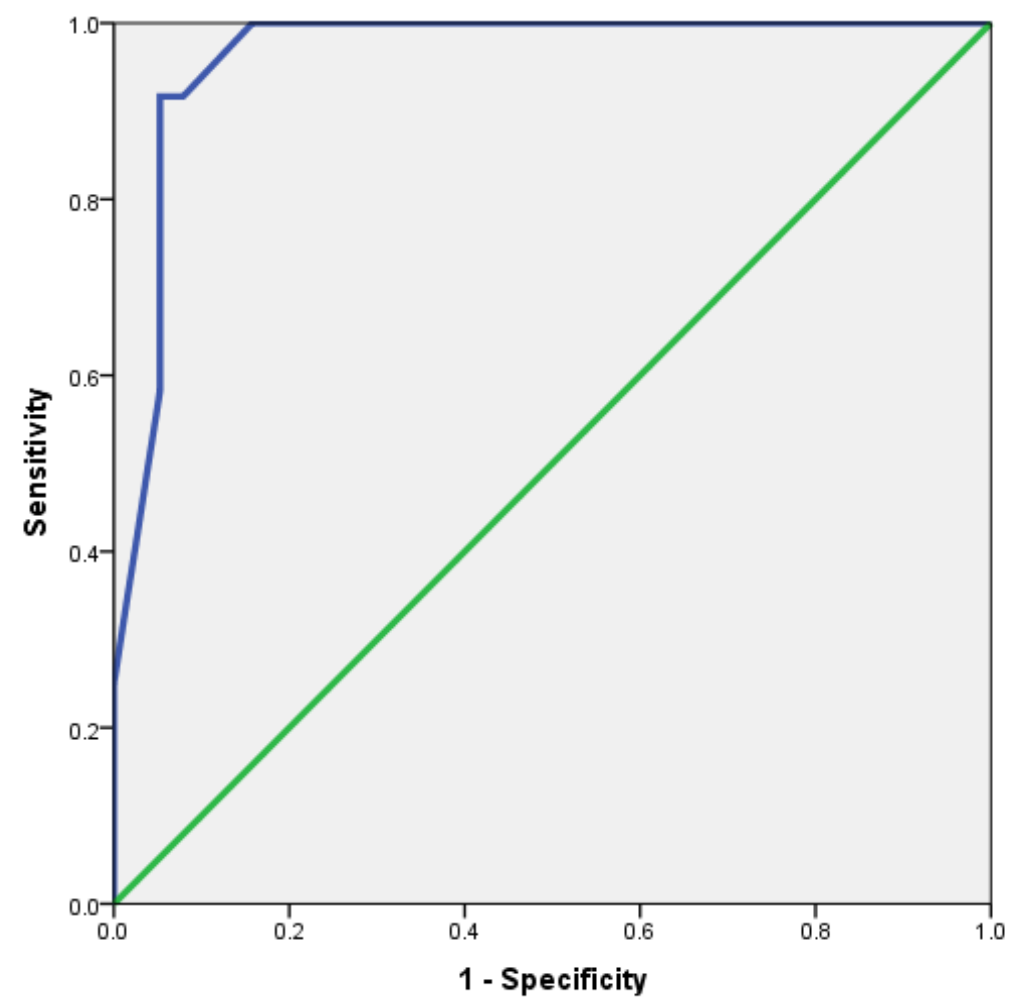

Figure (1): ROC curve showing performance of plasma GST in detection of acute kidney injury among the studied patients. 


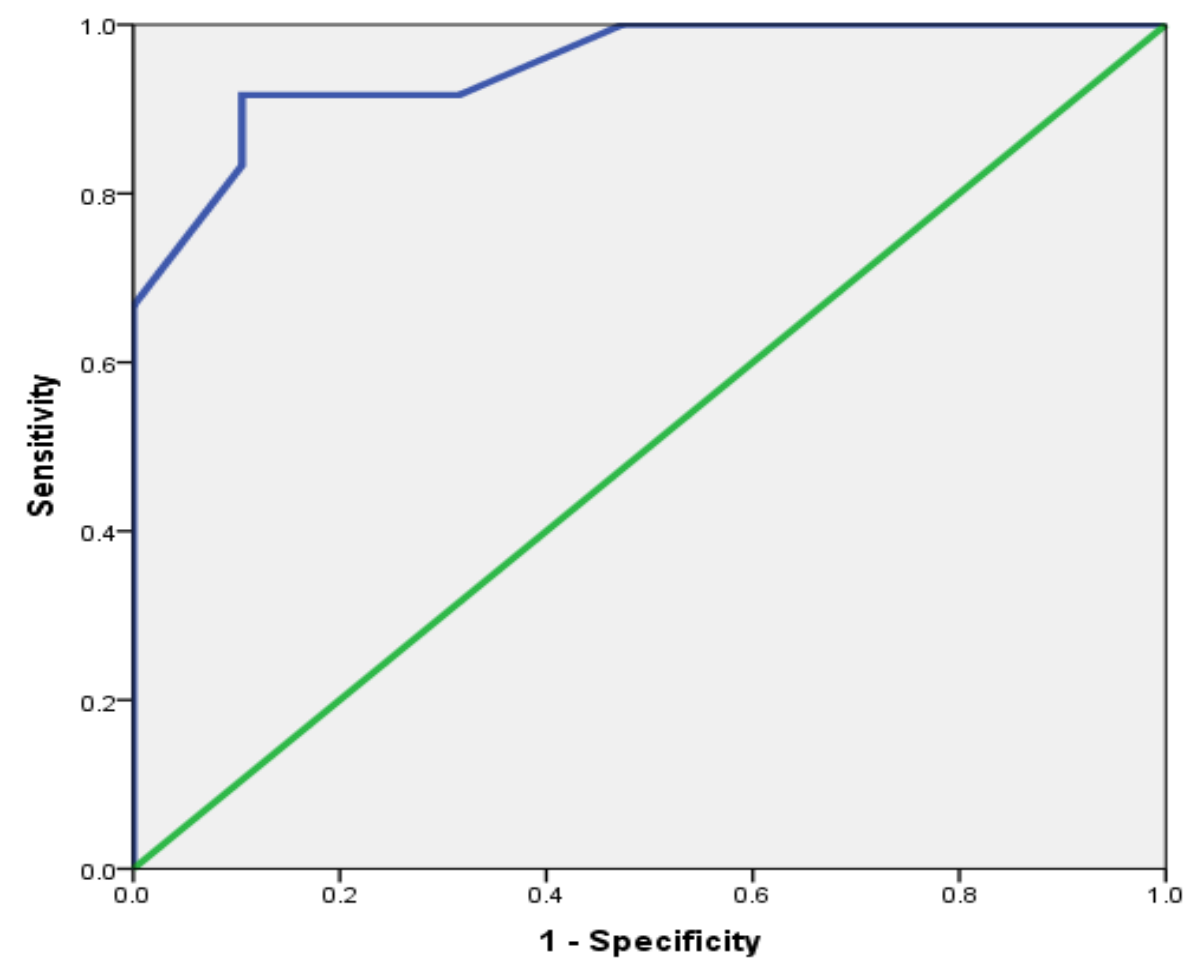

Figure (2): ROC curve showing performance of urinary GST in detection of acute kidney injury among the studied patients.

\section{DISCUSSION}

Acute kidney injury (AKI) is common in critically ill children admitted to intensive care. The etiology of AKI is multifactorial and the incidence varies between 1 and $41 \%$, probably due to the different definitions used in clinical studies ${ }^{(10)}$. The term AKI has largely replaced acute renal failure, as it more clearly defines renal dysfunction as a continuum rather than a discrete finding of failed kidney function. Pediatric AKI presents with a wide range of clinical manifestations from a minimal elevation in serum creatinine to anuric renal failure, and it occurs in a variety of clinical settings ${ }^{(\mathbf{1 1})}$.

Glutathione S-transferase comprises a multigene family of detoxification enzymes present in many organs with expression in specific tissues. These enzymes are significant in catalyzing the conjugation of many electrophilic substances to glutathione. Based on immunological, biochemical, and structural properties, soluble GS is separated in four basic classes: alpha, mu, pi, and theta. GST Pi has a significant role in protecting cells from cytotoxic and carcinogenic agents and is expressed in different concentrations in normal tissues and in a different concentration in different types of cells ${ }^{(\mathbf{1 2})}$.

Glutathione S-transferase pi can be detected in urine after renal tubular damage, and as a free radical scavenger, it can help decrease the extent of tubular damage. The GST Pi isoform is present in proximal tubules and Bowman's capsule until the 35th week of gestation. After this time, the isoenzyme is downregulated in proximal tubules and Bowman's capsule, and expression is restricted to distal tubular cells and collecting tubules. ${ }^{(13)}$.

In the current study, frequency of AKI was (24\%), representing (12) cases, out of (50) cases admitted to the PICU Zagazig University Children Hospital.

As regard to the incidence of AKI in different studies, it ranged from $30.6 \%$ to $35.8 \%$ (1415). Plotz et al. (16) and Akcan et al. ${ }^{(7)}$ reported incidence of AKI respectively (58\%) and (82\%). This variation can be explained by specific epidemiological characteristics according to the area of study. The high incidence of AKI on admission suggests that future studies that seek to assess risk factors for development of this complication should include data obtained prior to PICU admission and appears to indicate an unmet need for strict monitoring of renal function in the emergency department.

The present study demonstrated that, there was no significant difference between the (AKI) and (Non AKI) groups regarding the age, height, weight and gender in agreement with a previous study ${ }^{(15)}$.

A previous study by Mehta et al. ${ }^{\left({ }^{(17)} \text {, did }\right.}$ not agree with ours regarding age who found that younger age was independent risk factor for AKI in their study. Cabral et al. ${ }^{(18)}$ reported a significant relation between AKI and age, height and weight.

For outcome between (AKI) and (NonAKI) Groups, there was statistically non- significant 
difference between both groups. In our present study (Non-AKI) group was twice times bigger in mortality than that of (AKI) group, this is may be due to small number of AKI cases. It is not in agreement with Friere et al. ${ }^{(15)}$, who reported that the mortality in AKI cases was ten times bigger than that in non-AKI cases. Plotz et al. ${ }^{(16)}$ identified a five times bigger mortality in AKI cases than that in Non-AKI cases. Akcan et al. ${ }^{(7)}$ found no statistically significant difference for both groups' mortality. Hoste et al. (19) identified three times bigger mortality rates in the exposed group. Ostermann and Chang ${ }^{(14)}$ identified that AKI patients had a four times bigger mortality versus non-AKI patients. This can be explained by that AKI is associated with a number of life-threatening complications, which increase the mortality rate in these cases.

In the present study the (AKI) group was subdivided into three subgroups representing the classes of AKI (severity) regarding pRIFLE: Class (R) Risk, Class (I) injury and Class (F) failure. Frequency of (R) class is $25 \%$, frequency of (I) class is $41.7 \%$, frequency of $(\mathrm{F})$ class is $33.3 \%$, the AKI level incidence was variable at different studies as Friere et al., (15) reported that the maximal RIFLE score found during the patients stay was $39.1 \%$ for class (R), $37.2 \%$ for class (I) and $21.8 \%$ for class ( F) while Akcan et al. ${ }^{(7)}$ found $48.8 \%, 26 \%$ and 25.2\%, respectively. Plotz et al. (16) reported incidences of $52 \%, 37 \%$ and $11 \%$, respectively.

In a study by Mehta et al. ${ }^{(20)}$, maximum cases of AKI had Stage 1(65.8\%), followed by Stage $2(17.8 \%)$ and Stage 3(16.4\%). Similar pattern of AKI level (R, I, F) was reported by Akcan et al. ${ }^{(7)}$, i.e., $48.8 \%, 26 \%, 25.2 \%$, and Plötz et al. ${ }^{(16)}$, i.e., $52 \%, 37 \%, 11 \%$, respectively.

This variability of incidences can be explained can be attributed to different populations studied, and the different ICU characteristics.

Our study showed that, plasma and urine GST Pi was highly sensitive biomarker for early detection of AKI in pediatric cases of PICU (100\% and $91.7 \%$ respectively). This was in agreement with Coca et al. (21), regarding (urine GST Pi) who reported that, urine glutathione-S-transferase-pi performed best for facilitating early diagnosis of AKI.

Sundberg et al. ${ }^{(22)}$, showed that, two GSTs (alpha and $\mathrm{Pi}$ ) are released in urine during renal injury, which makes them a very early indicator of tubular injury. This is in agreement with our study because of GST Pi in urine and plasma is highly sensitive biomarker for early detection of AKI in pediatric intensive care unit.

Numerous studies have evaluated urinary GST as a biomarker of AKI in adults and children and have emphasized alpha GST and GST Pi as having a potential role in the diagnostic evaluation of AKI ${ }^{(23-24)}$. This was in agreement with our study because of GST pi was highly sensitive indicator in early detection of AKI in PICU. This can be supported by the finding that there is significant negative correlation between plasma, urinary GST and estimated creatinine clearance.

The strength of the current study is being prospective study that started with patients admitted to PICU and were followed up for development of AKI and also can identify actual role of GST in AKI.

The study had some limitations. The number of the participants was not large and being applied in one center. So, large scale multicenteric studied should be applied to verify role of GST in pathogenesis of AKI. Special attention should be applied to decrease incidence of AKI in PICU.

\section{CONCLUSION}

It could be concluded that AKI had significant incidence in PICU admission. The conclusion of our study is that high levels of plasma and urine GST Pi after admission in PICU are associated with an increased development of AKI in critically ill children in PICU. Our data demonstrated that GST $\mathrm{Pi}$ is a valuable tool (because of its high sensitivity and specificity) for early diagnosis of AKI and prediction of prognosis after admission in PICU which keep morbidity and mortality are less.

Funding: None to declare

Conflict of Interest: None to declare

\section{REFERENCES}

1. Andreoli $S$ (2009): Acute kidney injury in children. Pediatr Nephrol., 24: 253-63.

2. Chawla L, Bellomo R, Bihorac A (2017): Outcome of acute kidney injury. Nat Rev Nephrol., 5(1): 1-7.

3. Schetz M, Gunst J, Van den Berghe G (2014): The impact of using estimated GFR versus creatinine clearance on the evaluation of recovery from acute kidney injury in the ICU. Intensive Care Med., 40(11):1709-17.

4. Thomas M, Blaine C, Dawnay A, Devonald M et al. (2015): The definition of acute kidney injury and its use in practice. Kidney Int., 87:62-73.

5. Ostermann M, Joannidis M (2015): Biomarkers for AKI improve clinical practice: no.Intensive Care Med., 41(4):618-22.

6. Board P, Menon D (2013): Glutathione transferases, regulators of cellular metabolism and physiology. Biochimica et Biophysica Acta., 1830 (5): 32673288.

7. Akcan-Arikan A, Zappitelli M, Loftis $L$ et al. (2007): Modified RIFLE criteria in critically ill children with acute kidney injury. Kidney Int., 71:1028-1035. 
8. Kidney Disease Improving Global Outcomes (2012): Acute Kidney Injury Work Group: KDIGO Clinical Practice Guideline for Acute Kidney Injury. Kidney Inter Suppl., 2: 1-138.

9. Schwartz G, Brion L, Spitzer A (1987): The use of plasma creatinine concentration for estimating glomerular filtration rate in infants, children, and adolescents. Pediatr Clin North Am., 34(3):571-90.

10. Krishnamurthy $S$ (2013): Incidence and etiology of acute kidney injury in Southern India: author's reply. Indian J Pediatr., 80: 797-803.

11. Askenazi D (2011): Evaluation and management of critically ill children with acute kidney injury. Curr Opin Pediatr., 23: 201-207.

12. Hayes J, Flanagan J, Jowsey I (2005): Glutathione transferases. Annu Rev Pharmacol Toxicol., 45: 5188 .

13. Townsend D, Manevich Y, He L et al. (2009): Novel role for glutathione S-transferase $\pi$ regulator of protein S-glutathionylation following oxidative and nitrosative stress. J Biol Chem., 284(1):436-445.

14. Ostermann M, Chang $R$ (2007): Acute kidney injury in the intensive care unit according to RIFLE. Crit Care Med., 35(8):1837-42.

15. Freire K, Bresolin N, Farah A et al. (2010): Acute kidney injury in children: incidence and prognostic factors in critically ill patients. Rev Bras Ter Intensiva, 22(2):166-174

16. Plötz F, Bouma A, van Wijk J et al. (2008): Pediatric acute kidney injury in the ICU: an independent evaluation of pRIFLE criteria. Intensive Care Med., 34(9):1713-7.

17. Metha R, Pascual M, Soroko S et al. (2002): Diuretics, mortality and non-recovery of renal function in acute renal failure. JAMA., 228:25472553.

18. Cabral F, Garcia P, Mattiello $R$ et al. (2015): Influence of acute kidney injury defined by the Pediatric Risk, Injury, Failure, Loss, End-stage renal disease (pRIFLE) score on the clinical course of pediatric intensive care unit patients. Pediatric Critical Care Medicine, 16(8): 1-21

19. Hoste E, Clermont G, Kersten A et al. (2006): RIFLE criteria for acute kidney injury are associated with hospital mortality in critically ill patients: a cohort analysis. Crit Care, 10(3):73-78.

20. Mehta $P$, Sinha A, Sami A et al. (2012): Incidence of acute kidney injury in hospitalized children. Indian Pediatr., 49: 537-542.

21. Coca S, Yalavarthy $\mathrm{R}$, Concato $\mathrm{J}$ et al. (2008): Biomarkers for the diagnosis and risk stratification of acute kidney injury: a systematic review. Kidney Int., 73:1008-1016.

22. Sundberg A, Appelkvist E, Dallner G et al. (1994): Glutathione transferases in the urine: sensitive methods for detection of kidney damage induced by nephrotoxic agents in humans. Environ Health Perspect., 102:293-296.

23. Walshe C, Odejayi F, Ng S et al. (2009): Urinary glutathione $\mathrm{S}$-transferase as an early marker for renal dysfunction in patients admitted to intensive care with sepsis. Crit Care Resusc., 11:204-209.

24. McMahon B, Koyner J, Murray P (2010): Urinary glutathione S-transferases in the pathogenesis and diagnostic evaluation of acute kidney injury following cardiac surgery: a critical review. Curr Opin Crit Care, 16(6):550-555. 